\title{
Selling to strategic customers with cost uncertainty
}

\author{
Guodaohou Song and Xiaofang Wang ${ }^{*}$ (i)
}

\author{
* Correspondence: xiaofang_wang@ \\ ruc.edu.cn \\ Business school, Renmin University \\ of China, Beijing 100872, China
}

\begin{abstract}
Production cost can be influenced by previous sales in an uncertain way. In reality, production cost may decrease in the number of initial buyers due to the learning effect, or increase in the number of initial buyers due to the quality-improving pressure from negative comments of unhappy users. Taking this uncertainty into account, this paper studies the optimal intertemporal pricing strategies of a firm when selling to strategic customers in two periods where production cost in the second period randomly changes with the number of buyers in the first period. Our results suggest how firms should adjust their optimal pricing strategies under different market circumstances.
\end{abstract}

Keywords: Strategic customers, Cost, Uncertainty, Pricing, Dynamic pricing, Price commitment, Optimal pricing, Intertemporal pricing

\section{Introduction}

In practice, production cost can be influenced by previous sales. On one hand, production cost can be reduced when the yield is increasing. For example, such cost reduction may come from learning by doing. As the production quantity increases, workers become more familiar with their jobs and they accumulate experience/knowledge to improve the process and reduce the cost. Such cost reduction increases with the quantity produced previously. On the other hand, production cost may increase with the quantity produced previously. One example is from the e-commerce, where online reviews are more important for a firm. The increase of negative reviews (possibly from the increase of initial users) will pressure the firm to increase production cost in order to recover its reputation. In general, more initial sales can either increase or decrease production cost in the future and this impact is uncertain.

Multi-period sales are common practices used by many firms. But the uncertain influence of the initial sale on the later-period production cost has placed a great challenge in optimizing pricing strategies facing strategic customers. In previous literature, the seminal work by Besanko and Winston (1990) find that compared to myopic customers, strategic customers have a higher price elasticity because they may choose to delay purchase. Then Cachon and Swinney (2009), Liu and van Ryzin (2008, 2011), and $\mathrm{Su}(2007,2010)$ investigate the intertemporal pricing framework with strategic customers. Yu et al. (2016) model the strategic behavior of customers who wait for more information about the quality of product. In our paper, we use a similar

(c) The Author(s). 2020 Open Access This article is distributed under the terms of the Creative Commons Attribution 4.0 International License (http://creativecommons.org/licenses/by/4.0/), which permits unrestricted use, distribution, and reproduction in any medium, provided you give appropriate credit to the original author(s) and the source, provide a link to the Creative Commons license, and indicate if changes were made. 
intertemporal framework as these papers. However, these studies mainly focus on the impact of strategic behavior or social learning while we consider the impact of cost uncertainty. There are a few papers modeling the uncertain production cost. Sibdari and Pyke (2014) consider random costs under a duopoly model within infinite periods. They mainly focus on using the randomness in the rival's cost to achieve a higher profit. Shum et al. (2016) study an intertemporal pricing problem of a monopolist considering the uncertain cost reduction. However, different from these papers, we model cost uncertainty as the uncertain influence of initial sales instead of a random term independent of initial sales. Our paper mainly studies the impact of such cost uncertainty on the firm's pricing decisions. We summarize our research questions as follows:

1. With the cost uncertainty, what are the optimal prices under two main pricing strategies - Dynamic Pricing and Price Commitment respectively?

2. What are the impacts of different parameters on the optimal prices and pricing strategy decision?

The remainder of this paper is organized as follows. In section 2, we present a brief description of our model. In section 3, we show the optimal prices and profits under different pricing strategies. Section 4 compares two pricing strategies. In section 5 , we conclude the paper with some discussions.

\section{Model}

We consider a single monopolistic firm selling products to a large market over two periods. The size of the market is deterministic and is normalized as 1. Each customer can purchase at most one product. The prices in two periods are denoted by $p_{1}$ and $p_{2}$ respectively. The firm who is risk neutral decides the prices in both periods to maximize expected profit. The sales volume in the two stages are $\lambda_{1}$ and $\lambda_{2}$ respectively, so $\lambda_{1}+\lambda_{2} \in[0,1]$.

We assume customers are heterogeneous in their intrinsic valuations of the product, $v$, which is uniformly distributed in $[0,1]$. This implies that customers may estimate the product's value differently according to their own experiences, preferences and information in hand. Then the customer's utilities $U$ if purchasing the product at period $i(i=1,2)$ are as follows:

$$
\begin{aligned}
& U_{1}=v-p_{1} . \\
& U_{2}=\theta\left(v-p_{2}\right) .
\end{aligned}
$$

Since the customers are strategic, we use the parameter $\theta(0<\theta<1)$ to describe the patience of customers or the opportunity cost of delaying purchase, similar to the models in Cachon and Swinney (2009), and Papanastasiou and Savva (2017). Since customers discount their utilities for later purchases, it can be expected that customers with high valuations purchase early in the equilibrium. ${ }^{1}$ We assume a customer with the certain thresholds $\bar{v}$ will find it indifferent to purchasing in either period. Then customers with valuations higher than or equal to $\bar{v}$ will purchase the product in the first

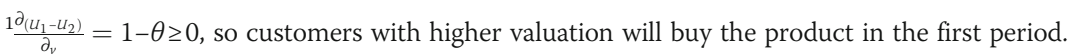


period and customers with valuations lower than $\bar{v}$ will wait till the second period. Thus the first-period demand $\lambda_{1}=1-\bar{v}$. Similarly, we assume a customer with the certain threshold $\underline{v}(0<\underline{v}<\bar{v})$ will find it indifferent to purchasing in the second period or not purchasing. So customers with valuations from $\underline{v}$ to $\bar{v}$ will purchase the product in the second period, which means $\lambda_{2}=\bar{v}-\underline{v}$. The unit production cost in the first period is $c(c<1)$. Then the unit production cost in the second period is

$$
c_{2}=c-\left(\alpha+\beta \lambda_{1}\right),
$$

where $\alpha$ is a positive cost reduction due to technology advancement and $\beta$ measures the uncertain impact from the initial sale $\lambda_{1}$. Without loss of generality, we assume $\beta$ has a mean of zero and a variance of $\sigma^{2}$ which is smaller than one. Thus the firm's problem is to maximize the total expected profit by determining the prices:

$$
\underset{p_{1}, p_{2} \geq 0}{\operatorname{maximize}} \pi=\pi_{1}+E \pi_{2}=\lambda_{1}\left(p_{1}-c\right)+E\left[\lambda_{2}\left(p_{2}-\mathrm{c}_{2}\right)\right] .
$$

\section{Model analysis}

In this section, we analyze the firm's problem under two different pricing strategies: dynamic pricing and price commitment. We analyze the firm's optimal decisions and compare the profits achieved under each pricing strategy in the next subsections.

\section{Dynamic pricing}

In the dynamic pricing setting, the firm announces the price of the second period at the end of the first period when the value of uncertain parameter $\beta$ is known. Under this strategy, we solve the problem backward by maximizing the profit in the second period first,

$$
\pi_{2}=\left[p_{2}-\left(c-\left(\alpha+\beta \lambda_{1}\right)\right)\right](\bar{v}-\underline{v}) .
$$

Since $\underline{v}$ is the threshold valuation of not buying in the second period, it can be solved by setting $U_{2}=\theta\left(\underline{\nu}-p_{2}\right)=0$. In addition $\lambda_{1}=1-\bar{v}$, so we obtain:

$$
\pi_{2}=\left[p_{2}-c+\alpha+\beta(1-\bar{v})\right]\left(\bar{v}-p_{2}\right) .
$$

It is obvious that the above profit function is concave in $p_{2}$. So we derive the optimal $p_{2}$ as a function of $\bar{v}$ and $\beta$,

$$
p_{2}^{*}(\bar{v}, \beta)=\frac{\bar{v}+c-\alpha-\beta(1-\bar{v})}{2} .
$$

Under the framework of rational expectation, the firm decides the price on the belief of customers' strategic behavior while the customers make their decisions by forecasting the firm's pricing decisions and other customers' choice. So given this $p_{2}^{*}$, the customer with the threshold $\bar{v}$ will find it indifferent to purchase in each period. In other words, $\bar{v}-p_{1}=\theta\left(\bar{v}-E\left[p_{2}^{*}(\bar{v}, \beta)\right]\right)$. Thus,

$$
\bar{v}=\frac{2 p_{1}-\theta(c-\alpha)}{2-\theta} .
$$

In this case, the firm's total expected profit is given by: 


$$
\pi=\left(p_{1}-c\right)(1-\bar{v})+E\left[\pi_{2}^{*}\left(p_{1}, \beta\right)\right],
$$

where $\pi_{2}^{*}\left(p_{1}, \beta\right)=\frac{(\bar{v}+\alpha-c)^{2}+2(\bar{v}+\alpha-c)(1-\bar{v}) \beta+(1-\bar{v})^{2} \beta^{2}}{4}$ is derived by plugging (7) into (6). The following proposition characterizes the optimal prices in each period. Note that under dynamic pricing strategy with uncertain consumption externality, if the firm sells in both periods, the optimal price in the second period is an expectation instead of a certain value due to the realization of the cost uncertainty.

Proposition 1. Under the dynamic pricing strategy, when $\alpha \leq \frac{(1-\theta)(1-c)}{1+\theta}$, the firm sells in both periods; when $\alpha>\frac{(1-\theta)(1-c)}{1+\theta}$, the firm only sells in the second period. Let $p_{1}^{D}$ and $p_{2}^{D}$ denote the optimal prices.

(1) When the firm sells in both periods,

$$
\begin{aligned}
p_{1}^{D} & =\frac{(2-\theta)\left(2-\theta-\sigma^{2}\right)+\alpha\left[2-\theta\left(2-\theta-\sigma^{2}\right)\right]+\left[2-\theta\left(\theta+\sigma^{2}\right)\right] c}{2\left(3-2 \theta-\sigma^{2}\right)}, E\left[p_{2}^{D}\right] \\
& =\frac{2-\theta-\sigma^{2}+\alpha\left(3 \theta+\sigma^{2}-2\right)+\left(4-3 \theta-\sigma^{2}\right) c}{2\left(3-2 \theta-\sigma^{2}\right)} .
\end{aligned}
$$

(2) When the firm only sells in the second period, $p_{2}^{D}=\frac{1+c-\alpha}{2}$.

Proposition 1 implies that when the speed of technology advancement is high (e.g. $\alpha$ $\left.>\frac{(1-\theta)(1-c)}{1+\theta}\right)$, strategic customers expect a low production cost and thus a low price in the second period. In this case, the firm maximizes the profit by selling the product only in the second period. Otherwise, the firm sells in both periods.

Corollary 1. Under the dynamic pricing strategy, when the firm sells in both periods,

(1) $\frac{\partial p_{1}^{D}}{\partial_{\alpha_{0}}}>0, \frac{\partial E\left[p_{2}^{D}\right]}{\partial \alpha_{\alpha_{D}}}>0$ if and only if $\sigma^{2}>2-3 \theta$;

(2) $\frac{\partial p_{1}^{\phi_{D}}}{\partial_{\sigma^{2}}}<0, \frac{\partial E\left[p_{2}\right]}{\partial_{\sigma^{2}}}<0$;

(3) $p_{1}^{D}$ can be increasing or decreasing in $\theta, \frac{\partial E\left[p_{2}^{D}\right]}{\partial_{\theta}}>0$.

First, as technology advances ( $\alpha$ increases), the firm produces the product at a lower unit cost and thus obtains a higher profit in the second period. So the firm increases the price in the first period to shift sales from the first period to the second period to earn more profits $\left(\frac{\partial p_{1}^{D}}{\partial_{\alpha}}>0\right)$. Regarding the second-period price, there are two effects. On one hand, as $\alpha$ increases, since the first-period price increases, strategic buyers with relatively high valuations change their purchasing time from the first period to the second period. Then the firm is allowed to increase the second-period price to reap more profits from these customers, which is called as the superior effect. On the other hand, some potential customers with low valuations who decided not to purchase originally may decide to buy in the second period. Then the firm may decrease the second-period price to attract such customers, which is called as the inferior effect. When the cost reduction is uncertain or customers are patient $\left(\sigma^{2}>2-3 \theta\right)$, the superior effect dominates, the firm mainly targets at customers changing their purchasing time and thus $\frac{\partial E\left[p_{2}^{D}\right]}{\partial_{\alpha}}>0$. When cost reduction is certain and customers are impatient $\left(\sigma^{2} \leq 2-3 \theta\right)$, the inferior effect dominates, the firm mainly targets at customers who just enter the market in the second period, and thus $\frac{\partial E\left[p_{2}^{D}\right]}{\partial_{\alpha}} \leq 0$. 
Second, as uncertainty increases $\left(\sigma^{2}\right.$ increases), the uncertain component $\beta \lambda_{1}$ plays a more important role in the second-period production cost. Then the firm decreases the first-period price (i.e., $\frac{\partial p_{1}^{D}}{\partial_{\sigma^{2}}}<0$ ). The reason is explained as follows: On one hand, if the uncertain cost is realized to be cost reduction (i.e. positive $\beta$ ), the firm should increase initial sales by decreasing the first-period price in order to generate a greater cost reduction in the second period. On the other hand, if the uncertain cost is realized to be cost increase (i.e. negative $\beta$ ), the firm can always use the second-period price as a lever to alleviate this effect. Thus the gain of increasing the first-period price in the former case is larger than the loss in the latter case. Resulting from a lower first-period price and a smaller remaining market ( $\bar{v}$ is smaller), the firm should decrease the secondperiod price in expectation. This is different from the findings in Shum et al. (2016). They find that price level is independent on cost uncertainty because they assume the uncertainty does not depend on initial sales.

Third, when customers are more strategic, or equivalently, more likely to wait ( $\theta$ increases), the firm will decrease the first-period price to alleviate customers' waiting behaviors in most cases (i.e., $\frac{\partial p_{1}^{D}}{\partial_{\theta}}<0$ ). However, when $\alpha$ is so large that the second period is very attractive to the customers, the firm will increase the first-period price to encourage customers with high valuation to buy in the second period (i.e., $\frac{\partial p_{1}^{D}}{\partial_{\theta}} \geq 0$ ). It is intuitive when the customers are more strategic, the firm is able to increase the price in the second period (i.e., $\frac{\partial E\left[p_{2}^{D}\right]}{\partial_{\theta}}>0$ ).

The next proposition characterizes the firm's optimal expected profit under dynamic pricing.

Proposition 2. Let $\pi^{D}$ be the optimal expected profit of the firm under dynamic pricing.

(1) When the firm sells in both periods,

$$
\pi^{D}=\frac{(2-\theta)^{2}-\sigma^{2}+2 \alpha\left[2-(2-\theta) \theta-\sigma^{2}\right]+\alpha^{2}\left(4+\theta^{2}-\sigma^{2}\right)-c\left\{2(2-\theta)^{2}+2 \alpha[2-(2-\theta) \theta]-2(1+\alpha) \sigma^{2}-\left[(2-\theta)^{2}-\sigma^{2}\right] c\right\}}{4\left(3-2 \theta-\sigma^{2}\right)} .
$$

(2) When the firm only sells in the second period, $\pi^{D}=\frac{(1+\alpha-c)^{2}}{4}$.

Corollary 2. Under the dynamic pricing strategy, when the firm sells in both periods,

(1) $\frac{\partial t^{D}}{\partial_{\alpha}}>0$.

(2) $\frac{\partial I^{D}}{\partial_{\sigma^{2}}}>0$.

(3) $\frac{\partial^{\sigma^{2}}}{\partial_{\theta}}<0$.

It is intuitive that technology advancement reduces the unit production cost in the second period and thus increases the profit (i.e., $\frac{\partial \pi^{D}}{\partial_{\alpha}}>0$ ). As shown in Shum et al. (2016), uncertainty is always beneficial for the firm under dynamic pricing (i.e., $\frac{\partial \pi^{D}}{\partial_{\sigma^{2}}}>0$ ). The reason is similar to our discussions for Proposition 1: If the uncertain cost is realized as a reduction, it makes the firm earn more profits in the later sales due to a lower unit cost. If the uncertain cost is realized as an increase, the firm can use the price in the second period as a lever to alleviate this effect. Consistent with previous literature, the firm's profit decreases when 
customers become more patient (i.e., $\frac{\partial I^{D}}{\partial_{\theta}}<0$ ), because the customers would wait in anticipation of the price decrease, which hurts the firm's profit. In other words, when the customers are more patient, the firm is not able to utilize price discrimination over time to get more profits.

\section{Price commitment (PC)}

In the price commitment setting, the firm announces the prices in both periods before customers decide when to purchase and the realization of $\beta$. The utility of a customer with valuation $\bar{v}$ satisfies $\bar{v}-p_{1}=\theta\left(\bar{v}-p_{2}\right)$, or equivalently,

$$
\bar{v}=\frac{p_{1}-\theta p_{2}}{1-\theta} .
$$

As in dynamic pricing, the valuation threshold of not buying in the second period is given by setting $U_{2}=\theta\left(\underline{v}-p_{2}\right)=0$. However, the firm determines both prices based on the expected uncertain cost in the second period. So the total expected profit of the firm is given by

$$
\pi=\left(p_{1}-c\right)(1-\bar{v})+\left(p_{2}-E\left[c_{2}\right]\right)(\bar{v}-\underline{v})
$$

where $E\left[c_{2}\right]=c-\alpha$ according to the assumptions that $c_{2}=c-\left(\alpha+\beta \lambda_{1}\right)$ and $\beta$ has a mean of zero. The following proposition characterizes the optimal prices under price commitment.

Proposition 3. Under price commitment strategy, when $\alpha \leq \frac{(1-\theta)(1-c)}{1+\theta}$, the firm sells in both periods; when $\alpha>\frac{(1-\theta)(1-c)}{1+\theta}$, the firm only sells in the second period. Let $p_{1}^{C}$ and $p_{2}^{C}$ denote the optimal prices.

(1) When the firm sells in both periods, $p_{1}^{C}=\frac{2+\alpha+(1+\theta) c}{3+\theta}, p_{2}^{C}=\frac{1+\theta-\alpha+2 c}{3+\theta}$.

(2) When the firm only sells in the second period, $p_{2}^{C}=\frac{1+c-\alpha}{2}$.

Different from dynamic pricing, the firm prices the product in advance in anticipation of what would happen in the future and thus only the expectation of the uncertain cost would affect the firm's decision. Then the prices are independent on the uncertainty level $\sigma^{2}$. But with the same condition $\left(\alpha>\frac{(1-\theta)(1-c)}{1+\theta}\right)$ as in dynamic pricing, the firm only sells the product in the second period and otherwise the firm sells the product in both periods.

Corollary 3. Under the price commitment strategy, when the firm sells in both periods,

(1) $\frac{\partial p_{1}^{C}}{\partial_{\alpha_{C}}}>0, \frac{\partial p_{2}^{C}}{\partial_{\alpha_{C}}}<0$.

(2) $\frac{\partial p_{1}^{C}}{\partial_{\theta}}<0, \frac{\partial p_{2}}{\partial_{\theta}}>0$

First, as technology advances ( $\alpha$ increases), similar to that under dynamic pricing, $\frac{\partial p_{1}^{C}}{\partial_{\alpha}}>0$. However, under the price commitment, the second-period price is decreasing in $\alpha$. This is because the firm has no ability to respond to uncertainty or in other words, the firm can only anticipate a cost reduction due to technology advance. Therefore in this case, the inferior effect always dominates and thus 
the price decreases when technology advances faster $\left(\frac{\partial p_{2}^{c}}{\partial_{\alpha}}<0\right)$.

Second, when the customers become more patient ( $\theta$ increases), consistent with findings in Besanko and Winston (1990) and Shum et al. (2016), the advantage of price commitment is constraining the waiting behavior of the strategic customer and when the firm sells in both periods, the optimal pricing path is always markdown. ${ }^{2}$ Thus when the customers become more patient, the firm commits to not decreasing the second-period price to constrain the waiting behavior of strategic customers and decrease the first-period price to encourage them to purchase early (i.e., $\frac{\partial p_{1}^{C}}{\partial_{\theta}}<0$ and $\frac{\partial p_{2}^{C}}{\partial_{\theta}}>0$ ).

The next proposition characterizes the firm's optimal expected profit under the price commitment strategy.

Proposition 4. Let $\pi^{C}$ be the optimal expected profit of the firm under the price commitment.

(1) When the firm sells in both periods, $\pi^{C}=\frac{1-\theta+\alpha(1+\alpha-\theta)-c(1-\theta)(2+\alpha-c)}{(1-\theta)(3+\theta)_{2}}$.

(2) When the firm only sells in the second period, $\pi^{C}=\frac{(1+\alpha-c)^{2}}{4}$.

Corollary 4. Under the price commitment strategy, when the firm sells in both periods,

(1) $\frac{\partial \pi^{C}}{\partial_{\alpha}}>0$.

(2) $\frac{\partial \pi^{C}}{\partial \theta}<0$.

Under price commitment the firm is not able to respond to the cost uncertainty dynamically and so the optimal expected profit does not depend on $\sigma^{2}$. It is intuitive that the firm earns more profit as technology advances and less profit when customers are more patient.

\section{Comparisons of the two pricing strategies}

By comparing the optimal profits under two pricing strategies, we obtain the following proposition.

Proposition 5.

(1) When $\alpha \leq \frac{(1-\theta)(1-c)}{1+\theta}$, dynamic pricing leads to a higher expected profit if $\sigma^{2} \geq \theta^{2}$ and price commitment leads to a higher expected profit otherwise.

(2) When $\alpha>\frac{(1-\theta)(1-c)}{1+\theta}$, dynamic pricing and price commitment achieve the same expected profits.

Proposition 5 is illustrated in Fig. 1: When the technology advancement is high or when customers are very patient $\left(\alpha>\frac{(1-\theta)(1-c)}{1+\theta}\right.$ or equivalently $\left.\theta>\frac{1-\alpha-c}{1+\alpha-c}\right)$, there is no difference between the two strategies because the firm sells products only in the second period (the white area). When the technology advancement is low or customers are not so patient $\left(\alpha \leq \frac{(1-\theta)(1-c)}{1+\theta}\right.$ or equivalently $\theta \leq \frac{1-\alpha-c}{1+\alpha-c}$ ), the firm should optimally use dynamic

${ }^{2} p_{1}^{C}-p_{2}^{C}=\frac{2 \alpha+(1-c)(1-\theta)}{3+\theta}$, which is always positive. 
pricing when facing high cost uncertainty or low customer patience (the dark gray area) or price commitment when facing low cost uncertainty or high customer patience (the gray area). This is because dynamic pricing can respond to uncertainty better while price commitment can deter waiting behaviors of customers better. Moreover, interestingly, when the firm sells in both periods, neither the technology advancement nor the basic cost affects the firm's choice between the two different pricing strategies; the boundary of pricing strategies is $\sigma^{2}=\theta^{2}$ as shown in Fig. 1. In contrast, Shum et al. (2016) find that the firm might prefer dynamic pricing when the technology advance effect is high. Such difference is due to different sources of the uncertainty.

\section{Conclusions and discussions}

Our paper mainly focuses on the pricing strategies of firms when facing the heterogeneous strategic customers and uncertain production cost. We examine the impact of two important drivers, technology advancement and cost uncertainty. First, the influence of technology advancement on the second-period price depends on the level of uncertainty and customer patience. If technology advances, when facing low leveled uncertainty or impatient customers, the firm decreases the price in the second period to attract customers with low valuations. In contrast, when facing high leveled uncertainty or patient customers, the firm increases the price in the second period to obtain more surplus from customers with high valuations who shift their purchasing time from the first period to the second period in consideration of technology advancement. Second, cost uncertainty benefits the firm, which is also found in Shum et al. (2016). However, when cost uncertainty is correlated with initial sales, we find the optimal price is influenced by the level of uncertainty under the dynamic pricing strategy, which is different from the findings in Shum et al. (2016). Finally, only cost uncertainty and customers' patience impact the firm's choice among pricing strategies, which is also different from

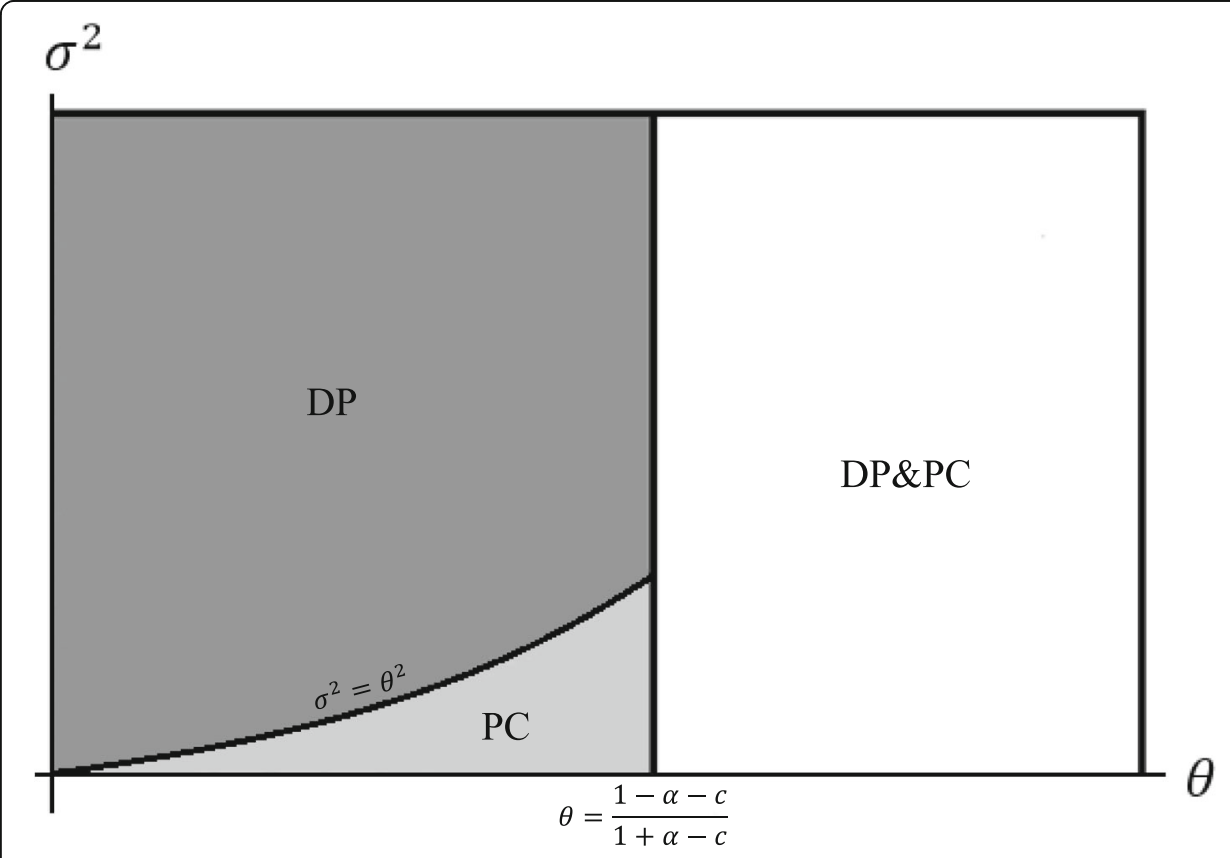

Fig. 1 The optimal pricing strategy Notes. $a=0.2, c=0.3 ; \mathrm{DP}=$ dynamic pricing; $\mathrm{PC}=$ price commitment 
Shum et al.'s (2016) results that the firm might prefer dynamic pricing under a significant technology advance effect.

There are several remaining research questions. First, we may extend our work to the strategies including price matching or pricing over multiple periods. Second, we can jointly study pricing decisions and other production decisions (inventory, capacity, etc.). Third, instead of a monopolistic seller, extending the model with uncertainty to a situation with competition might be interesting.

\section{Appendix}

\section{Proof of Proposition 1.}

The firm's problem has been given by:

$$
\begin{aligned}
& =p_{1}\left(1-\frac{2 p_{1}-\theta(c-\alpha)}{2-\theta}\right)+E \pi_{2}^{*}\left(p_{1}, \beta\right) \\
\underset{p_{1}}{\operatorname{maximize} \pi\left(p_{1}\right)} & =\frac{4\left(p_{1}+\alpha-c\right)^{2}-4(2-\theta)\left(p_{1}-c\right)\left[2 p_{1}+\theta(1+\alpha-c)-2\right]+\sigma^{2}\left[2 p_{1}+\theta(1+\alpha-c)-2\right]^{2}}{4(2-\theta)^{2}}
\end{aligned}
$$

$$
\frac{2 p_{1}-\theta(c-\alpha)}{2-\theta}-E\left[\frac{\frac{2 p_{1}-\theta(c-\alpha)}{2-\theta}+c-\alpha-\beta\left(1-\frac{2 p_{1}-\theta(c-\alpha)}{2-\theta}\right)}{2}\right] \geq 0 .
$$

Since $\frac{\partial_{\pi\left(p_{1}\right)}^{2}}{\partial_{p_{1}^{2}}^{2}}=\frac{2\left(2 \theta+\sigma^{2}-3\right)}{(2-\theta)^{2}}<0, \pi\left(p_{1}\right)$ is concave in $p_{1}$. By using the first-order condition, we get

$$
p_{1}^{*}=\frac{(2-\theta)\left(2-\theta-\sigma^{2}\right)+\alpha\left[2-\theta\left(2-\theta-\sigma^{2}\right)\right]+\left[2-\theta\left(\theta+\sigma^{2}\right)\right] c}{2\left(3-2 \theta-\sigma^{2}\right)} .
$$

The first constraint is used to test if there is sales volume in the first period. We plug $p_{1}^{*}$ into $1-\frac{2 p_{1}-\theta(c-\alpha)}{2-\theta} \geq 0$ and derive $\alpha \leq \frac{(1-\theta)(1-c)}{1+\theta}$. In other words, if $\alpha>\frac{(1-\theta)(1-c)}{1+\theta}$, there would be no sales in the first period. Solving this single selling period problem, $p_{2}^{D}=\frac{1+c-\alpha}{2}$.

Similarly, the second constraint is used to test if there is expected sales volume in the second period. We plug $p_{1}^{*}$ into this constraint and derive $\frac{-2+\theta+\sigma^{2}+\alpha\left(-4+\theta+\sigma^{2}\right)-c\left(-2+\theta+\sigma^{2}\right)}{2\left(-3+2 \theta+\sigma^{2}\right)} \geq 0$ which can always be satisfied so there is no situation where sales only occur in the first period.

So when $\alpha \leq \frac{(1-\theta)(1-c)}{1+\theta}$, the firm sells in both periods and $p_{1}^{D}=p_{1}^{*}=$ $\frac{(2-\theta)\left(2-\theta-\sigma^{2}\right)+\alpha\left[2-\theta\left(2-\theta-\sigma^{2}\right)\right]+\left[2-\theta\left(\theta+\sigma^{2}\right)\right] c}{2\left(3-2 \theta-\sigma^{2}\right)}$. According to (7) and (8), we derive $E\left[p_{2}^{D}\right]$ $=\frac{2-\theta-\sigma^{2}+\alpha\left(3 \theta+\sigma^{2}-2\right)+\left(4-3 \theta-\sigma^{2}\right) c}{2\left(3-2 \theta-\sigma^{2}\right)}$.

\section{Proof of Corollary 1.}

(1) $\frac{\partial p_{1}^{D}}{\partial_{\alpha}}=\frac{2-\theta\left(2-\theta-\sigma^{2}\right)}{2\left(3-\sigma^{2}-2 \theta\right)}>0 . \frac{\partial E\left[p_{2}^{D}\right]}{\partial_{\alpha}}=\frac{2-\sigma^{2}-3 \theta}{2\left(-3+\sigma^{2}+2 \theta\right)}$. Thus when $\sigma^{2}>2-3 \theta, \frac{\partial E\left[p_{2}^{D}\right]}{\partial_{\alpha}}>0$; when

$$
\sigma^{2} \leq 2-3 \theta, \frac{\partial E\left[p_{2}^{D}\right]}{\partial_{\alpha}} \leq 0 \text {. }
$$

(2) $\frac{\partial p_{1}^{D}}{\partial_{\sigma^{2}}}=\frac{(-2+\theta)[(1-\theta)(1-c)-\alpha(1+\theta)]}{2\left(3-\sigma^{2}-2 \theta\right)^{2}}$, which is non-positive under $\alpha \leq \frac{(1-\theta)(1-c)}{1+\theta} \cdot \frac{\partial E\left[p_{2}^{D}\right]}{\partial_{\sigma^{2}}}$ $=\frac{\alpha(1+\theta)-(1-\theta)(1-c)}{2\left(-3+\sigma^{2}+2 \theta\right)^{2}}$, which is non-positive under $\alpha \leq \frac{(1-\theta)(1-c)}{1+\theta}$. 
(3) $\frac{\partial p_{1}^{D}}{\partial_{\theta}}=\frac{-4+2 c(-2+\theta)(-1+\theta)+6 \theta-2\left[\alpha+\alpha(-3+\theta) \theta+\theta^{2}\right]+[3+5 \alpha-2(1+\alpha) \theta+c(-3+2 \theta)] \sigma^{2}+(-1+c-\alpha) \sigma^{4}}{2\left(-3+2 \theta+\sigma^{2}\right)^{2}}$, or equivalently, $\frac{1}{4}\left[-1+c-\alpha+\frac{\left(1+\sigma^{2}\right)\left[1+c\left(-1+\sigma^{2}\right)+5 \alpha-\sigma^{2}(1+\alpha)\right]}{\left(-3+\sigma^{2}+2 \theta\right)^{2}}\right]$, which is positive when (i) $1-$ $\sigma^{2}<\theta<\frac{3-\sigma^{2}}{2}-\frac{\sqrt{1-\sigma^{4}}}{2}$ and $\alpha>-1+c+\frac{2(1-c)\left(1+\sigma^{2}\right)}{-2-\sigma^{4}+2(3-\theta) \theta+\sigma^{2}(5-2 \theta)}$; or (ii) $\frac{3-\sigma^{2}}{2}-\frac{\sqrt{1-\sigma^{4}}}{2} \leq \theta$ $<1$, and negative otherwise. $\frac{\partial E\left[p_{2}^{D}\right]}{\partial_{\theta}}=\frac{(1-c)\left(1-\sigma^{2}\right)+\left(5-\sigma^{2}\right) \alpha}{2\left(-3+\sigma^{2}+2 \theta\right)^{2}}>0$.

\section{Proof of Proposition 2.}

When the firm sells in single period, according to Proposition 1, (2) is easy to be proved that $\pi^{D}=\frac{(1+\alpha-c)^{2}}{4}$. When the firm sells in both periods, plug $p_{1}^{*}$ into $\pi\left(p_{1}\right)$ we derive,

$$
\pi^{D}=\frac{(2-\theta)^{2}-\sigma^{2}+2 \alpha\left[2-(2-\theta) \theta-\sigma^{2}\right]+\alpha^{2}\left(4+\theta^{2}-\sigma^{2}\right)-c\left\{2(2-\theta)^{2}+2 \alpha[2-(2-\theta) \theta]-2(1+\alpha) \sigma^{2}-\left[(2-\theta)^{2}-\sigma^{2}\right] c\right\}}{4\left(3-2 \theta-\sigma^{2}\right)} .
$$

\section{Proof of Corollary 2.}

(a) $\frac{\partial \pi^{D}}{\partial \sigma}=\frac{(\alpha-1) \sigma^{2}-(1+\alpha-c) \theta^{2}-4 \alpha-2[1-(1-\theta) c]}{2\left(-3+\sigma^{2}+2 \theta\right)}>0$.

(b) $\frac{\partial \pi^{D}}{\partial \sigma^{2}}=\frac{[\alpha(1+\theta)-(1-\theta)(1-c)]^{2}}{4\left(-3+\sigma^{2}+2 \theta\right)^{2}}>0$.

(c) $\frac{\partial \pi^{D}}{\partial_{\theta}}=-\frac{[4(1-\theta)(1-c)-\alpha(1+\theta)]\left[\left(4-\theta-\sigma^{2}\right) \alpha+2-(1-c)\left(\theta+\sigma^{2}\right)\right]}{2\left(-3+\sigma^{2}+2 \theta\right)^{2}}$, which is negative under $\alpha \leq \frac{(1-\theta)(1-c)}{1+\theta}$.

\section{Proof of Proposition 3.}

The firm's problem is given by

$$
\begin{aligned}
& \underset{p_{1}, p_{2}}{\operatorname{maxmize}} \pi\left(p_{1}, p_{2}\right)=\left(1-\frac{p_{1}-\theta p_{2}}{1-\theta}\right)\left(p_{1}-c\right)+\left(\frac{p_{1}-\theta p_{2}}{1-\theta}-p_{2}\right)\left(p_{2}-E\left[c_{2}\right]\right), \\
& \text { s.t. } 1-\frac{p_{1}-\theta p_{2}}{1-\theta} \geq 0 \\
& \quad \frac{p_{1}-\theta p_{2}}{1-\theta}-p_{2} \geq 0
\end{aligned}
$$

We can prove that, $\frac{\partial \pi^{2}}{\partial_{p_{1}}^{2}}=\frac{2}{-1+\theta}<0, \frac{\partial \pi^{2}}{\partial_{p_{2}}^{2}}=\frac{2}{-1+\theta}<0$, and $\frac{\partial \pi^{2}}{\partial_{p_{1}}^{2}} \frac{\partial \pi^{2}}{\partial_{p_{2}}^{2}}-\left(\frac{\partial \pi^{2}}{\partial_{p_{1}} \partial_{p_{2}}}\right)^{2}=\frac{3+\theta}{1-\theta}>0$. In other words, $\pi\left(p_{1}, p_{2}\right)$ is jointly concave in $\left(p_{1}, p_{2}\right)$ thus the first-order condition is valid. Let $\frac{\partial \pi}{\partial_{p_{1}}}=0, \frac{\partial \pi}{\partial p_{2}}=0$. We solve $p_{1}^{*}=\frac{2+\alpha+(1+\theta) c}{3+\theta}, p_{2}^{*}=\frac{1+\theta-\alpha+2 c}{3+\theta}$. Similar to the analysis of dynamic pricing, the two constraints are used to test if there are sales in each period. Plug $p_{1}^{*}$ and $p_{2}^{*}$ into these constraints we derive, when $\alpha>\frac{(1-\theta)(1-c)}{1+\theta}$, there would be no sales in the first period. So the problem turns into a single selling period problem where it is easy to find out that $p_{2}^{C}=\frac{1+c-\alpha}{2}$.

So when $\alpha \leq \frac{(1-\theta)(1-c)}{1+\theta}$, the firm sells in both periods where $p_{1}^{C}=p_{1}^{*}$ and $p_{2}^{C}=p_{2}^{*}$.

\section{Proof of Corollary 3.}

(1) $\frac{\partial p_{1}^{C}}{\partial_{\alpha_{C}}}=\frac{1}{3+\theta}>0 . \frac{\partial p_{2}^{C}}{\partial_{\alpha}}=-\frac{1}{3+\theta}<0$.

(2) $\frac{\partial p_{1}^{C}}{\partial_{\theta}}=-\frac{2(1-c)+\alpha}{(3+\theta)^{2}}<0$. $\frac{\partial p_{2}^{C}}{\partial_{\theta}}=\frac{2(1-c)+\alpha}{(3+\theta)^{2}}>0$.

\section{Proof of Proposition 4.}


When the firm sells in single period, according to Proposition 3, (2) can be easily proved that $\pi^{C}=\frac{(1+\alpha-c)^{2}}{4}$. When the firm sells in both periods, plug $p_{1}^{C}$ and $p_{2}^{C}$ into $\pi\left(p_{1}, p_{2}\right)$ we derive,

$$
\pi^{C}=\frac{1-\theta+\alpha(1+\alpha-\theta)-c(1-\theta)(2+\alpha-c)}{(1-\theta)(3+\theta)} .
$$

\section{Proof of Corollary 4.}

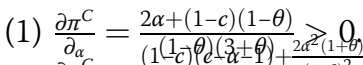

(2) $\frac{\partial \pi^{c}}{\partial_{\theta}}=\frac{(1-c) \theta\left(-(2 \pm-\theta)+\frac{2 \alpha^{2}(1-\theta)}{(1-\theta)^{2}}\right.}{(3+\theta)^{2}}$, which is negative under $\alpha \leq \frac{(1-\theta)(1-c)}{1+\theta}$.

\section{Proof of Proposition 5.}

According the analysis in the Model analysis and Comparisons of the two pricing strategies sections:

(1) When $\alpha \leq \frac{(1-\theta)(1-c)}{1+\theta}$,

$$
\begin{gathered}
\pi^{D}=\frac{(2-\theta)^{2}-\sigma^{2}+2 \alpha\left[2-(2-\theta) \theta-\sigma^{2}\right]+\alpha^{2}\left(4+\theta^{2}-\sigma^{2}\right)-c\left\{2(2-\theta)^{2}+2 \alpha[2-(2-\theta) \theta]-2(1+\alpha) \sigma^{2}-\left[(2-\theta)^{2}-\sigma^{2}\right] c\right\}}{4\left(3-2 \theta-\sigma^{2}\right)}, \\
\pi^{C}=\frac{1-\theta+\alpha(1+\alpha-\theta)-c(1-\theta)(2+\alpha-c)}{(1-\theta)(3+\theta)} .
\end{gathered}
$$

We compare the profits under the two strategies as,

$$
\begin{aligned}
& =\pi^{D}-\pi^{C} \\
\Delta \pi & =\frac{[(1-c)(1-\theta)-\alpha(1+\theta)]^{2}\left(\sigma^{2}-\theta^{2}\right)}{4(1-\theta)(3+\theta)\left(3-2 \theta-\sigma^{2}\right)} .
\end{aligned}
$$

It's obvious that when $\sigma^{2} \geq \theta^{2}$, dynamic pricing leads to the highest expected profit; when $\sigma^{2}<\theta^{2}$, price commitment leads to the highest expected profit.

(2) When $\alpha>\frac{(1-\theta)(1-c)}{1+\theta}, \pi^{D}=\pi^{C}=\frac{(1+\alpha-c)^{2}}{4}$, thus both strategies lead to highest profit.

Acknowledgements

For helpful comments, the authors are grateful to the participants at the Summer Doctorial Symposium at Renmin University of China.

Authors' contributions

All authors read and approved the final manuscript.

Authors' information

GS is a Ph.D. candidate at the Business school, Renmin University of China. His research interests lie in operations management and revenue management. XW is a professor in the Business school at Renmin University of China. Her research interests cover healthcare service management, revenue management and operations management.

\section{Availability of data and materials}

Not applicable.

\section{Competing interests}

The authors declare that they have no competing interests.

Received: 17 October 2019 Accepted: 29 November 2019

Published online: 07 January 2020

References

Besanko, D., \& Winston, W. L. (1990). Optimal price skimming by a monopolist facing rational consumers. Management Science, 36(5), 555-567. 
Cachon, G. P., \& Swinney, R. (2009). Purchasing, pricing, and quick response in the presence of strategic consumers. Management Science, 55(3), 497-511.

Dasu, S., \& Tong, C. (2010). Dynamic pricing when consumers are strategic: Analysis of posted and contingent pricing schemes. European Journal of Operational Research, 204(3), 662-671.

Liu, Q., \& Van Ryzin, G. J. (2008). Strategic capacity rationing to induce early purchases. Management Science, 54(6), 1115-1131.

Liu, Q., \& Van Ryzin, G. J. (2011). Strategic capacity rationing when customers learn. Manufacturing \& Service Operations Management, 13(1), 89-107.

Papanastasiou, Y., \& Savva, N. (2017). Dynamic pricing in the presence of social learning and strategic consumers. Management Science, 63(4), 919-939.

Shum, S., Tong, S., \& Xiao, T. (2016). On the impact of uncertain cost reduction when selling to strategic customers. Management Science, 62(3), 843-860.

Sibdari, S., \& Pyke, D. F. (2014). Dynamic pricing with uncertain production cost: An alternating-move approach. European Journal of Operational Research, 236(1), 218-228.

Su, X. (2007). Intertemporal pricing with strategic customer behavior. Management Science, 53(5), 726-741.

Su, X. (2010). Intertemporal pricing and consumer stockpiling. Operations Research, 58(4), 1133-1147.

Yu, M., Debo, L., \& Kapuscinski, R. (2016). Strategic waiting for consumer-generated quality information: Dynamic pricing of new experience goods. Management Science, 62(2), 410-435.

\section{Publisher's Note}

Springer Nature remains neutral with regard to jurisdictional claims in published maps and institutional affiliations.

Submit your manuscript to a SpringerOpen ${ }^{\circ}$ journal and benefit from:

- Convenient online submission

- Rigorous peer review

- Open access: articles freely available online

High visibility within the field

- Retaining the copyright to your article

Submit your next manuscript at $\boldsymbol{\nabla}$ springeropen.com 